\title{
Health Advisors in Organic Meet Sheep Farms: The Role of the Veterinarians
}

\author{
J. Cabaret ${ }^{*}, 1$, M. Benoit ${ }^{2}$, G. Laignel ${ }^{2}$ and C. Nicourt ${ }^{3}$ \\ ${ }^{I}$ INRA, UR 1282, IASP, Bat 213, 37380 Nouzilly, France \\ ${ }^{2}$ INRA, UR 506 Économie de l'élevage, Site de Theix, F-63122 Saint-Genès-Champanelle, France \\ ${ }^{3}$ INRA, UR 1216 RITME, 94205 Ivry, France
}

\begin{abstract}
Farmers receive advice from various categories of advisors' regarding the health management of their flocks. With respect to disease control strategies, treatment recommendations typically include either an allopathic synthetic drug approach or a more organic complementary line using alternative medicine, or indeed, a combination of the two. This study aimed to determine the proportion of treatment options in use by farmers and to correlate the treatment recommendations to the different categories of health advisor. A set of 34 meat sheep farms from the centre of France was used in the restricted sampling study, this included a representative sample of both organic $(n=7)$ and conventional $(n=$ 8) farms. Data on general health matters (e.g. cost of drugs, flock mortalities etc.) were collected from each of the farms. The study found conventional farms prescribed more to the recommendations made by veterinarians and spent more on synthetic allopathic drugs. The reverse situation was observed in organic farms which invested more money in alternative medicines as advised by mostly non-veterinarian health advisors, or guided by their own appreciation of disease management.
\end{abstract}

Keywords: Meat sheep, mortality, numerical productivity, advisor, veterinarian, health.

\section{INTRODUCTION}

The concept of organic agriculture first emerged in the 1880 's and has progressively developed more recently in response to a growing concern for environmental, animal and human health. It is comprised of four main principles, one of which is the Principle of Health [2]. This stipulates that Organic Agriculture should sustain and enhance the health of soil, plant, animal and human as one and indivisible from one another. This principle has since been well represented in the formation of regulations and legislations pertaining to organic agriculture [3]. Organic animal health management is inclined towards a "prevention is better than the cure" ideal however, the current reality is that diseases are present $[4,5]$ and require treatment [6]. Within the boundaries of organic farming, disease treatment options range from homeopathic to natural allopathic (mostly phytotherapy) and even include synthetic drugs depending on the severity of the disease [6]. Homeopathy and phytotherapy are however selected in preference to chemically-synthesised allopathic veterinary products or antibiotics provided that their therapeutic use is effective. The term "effective" raises the issue regarding the value of complementary and alternative medicines (CAM) in the treatment of disease. Homeopathy for instance, is one such therapeutic which is not considered as evidence based veterinary medicine [13]. The European Board of Veterinary Specialisation recognizes only scientific evidence-based medicine and specifies that specialists found practising treatments with no proof of efficacy run the risk of having

*Address correspondence to this author at the INRA, UR 1282, IASP, Bat 213, 37380 Nouzilly, France; Tel: +33 2 47427768; Fax: +33 2 47427774; E-mail: jacques.cabaret@ tours.inra.fr their specialist status withdrawn. Very likely, this will reduce the number of veterinarians willing to consider the potential merits of CAM, a preferred therapeutic of organic farmers. Animal health planning and surveillance can be a useful tool for farmers. For example, the identification of potential risks in the introduction or spread of disease, the early detection of disease presence and the implementation of effective measures to control existing problems, including the responsible use of medicines, can contribute towards improving flock health [7]. Such health plans should be carefully constructed preferably in collaboration with a veterinarian, although this was not found to be unanimously the case in South-West England in which only 10 out of 15 health plans had input from a veterinarian [7]. While some conventional farms may have designated dates for vaccinations or anthelmintic treatments [8], health planning in the aforementioned sense is not practised by most meat sheep farms. Instead, farmers submit to the external (top-down) prescriptions of veterinarians and technicians and also to the internal direction of other farmers or advisor's. If treatment patterns in agriculture are to be understood, particularly in organic husbandry [9], relying on the technical prescription is not enough. Determining what motivates farmers' healthcare behaviour, their perceptions, actions and decisions, is key to establishing sustainable health management and farm resilience to disease threats. The divide in organic versus conventional sheep meat farming considered in this paper may be used as a special case that resonates across all farming sectors. This study ascertains the role that veterinarians and other health advisors play in the health management decisions of farmers from organic and conventional meat sheep farms and equates it against the corresponding data collected on the general production/health of the farms. 


\section{MATERIALS AND METHODS}

\section{The Farms}

A previously established set of 34 organic and conventional meat sheep farms were studied, all of which were based in the Auvergne and Limousin regions in centre of France - regions with high concentrations of meat sheep farms. The structure (e.g. number of ewes, type of pastures, supplementary feeding etc.) and productivity (e.g. gross margin per ewe, numeric productivity, etc.) was recorded for each farm. A total of fifty variables were used to characterize the farms. Subsequent cluster analyses (data not shown) identified four groups of farms': conventional and organic which were further sub-dived relative to the topography of the farms' location e.g. Group 1: conventional/plain; Group 2: conventional/mountainous; Group 3: organic/plain; Group 4: organic/mountainous. As few of the organic farms were located in mountainous regions the sampling was restricted to the plain locations in order to maintain a balanced sampling of conventional (8: F2 to F9) and organic farms (7: F10 to F16). The proximity of the sampled meat sheep farms meant they were all exposed to similar climatic conditions (average rainfall: $850-1000 \mathrm{~mm} / \mathrm{year}$, average mean temperature: $10.9-11.4^{\circ} \mathrm{C}$ ). The farmers' relied primarily on the production of their sheep for income and had been involved in farming for several years prior to the study. They were considered to be representative of economically sustainable meat sheep farming.

\section{Farm Economical and Production Characteristics}

Each of the initial set of 34 farms was visited at the end of 2004. Typically, 1.5 days was spent on each farm for data collection and analysis, the results of which determined the farms to be further investigated via interview (see above). The interviews incorporated the following parameters [10]:

\section{Animal Mortality Rates}

- Mortalities of lambs (Mlamb)

- Mortality of ewes (Mewes)

\section{Animal Production}

- Numerical productivity of the flock (Numprod): this comprised of the number of lambs produced, the number sold, and the number of females kept on the farm for reproduction per ewe over a 12 month period,

- Fodder autonomy (Fodaut) : the percentage of fodder produced and consumed on the farmKilogram of food concentrate consumed per ewe (Kgconc)

\section{Economic Return (expressed in Euro Per Ewe)}

- Sheep gross margin: the difference of value between gross product (sheep production, state subsidies) and input for the flock

- Cost of reproductive hormone treatment (Hor)

- Veterinary costs (Vetcost)

- $\quad$ Cost of complementary drugs and minerals (Cam)

\section{The Open Interview on Animal Health}

The organic farms were interviewed in mid-September 2006 and the conventional ones in October 2007. Each interview (lasting between 1.5 - 2 hours) included a visit of the farm followed by an open discussion on sheep production and health problems. The discussion was recorded, transcribed into a Word file and then analysed. Based on the advisors referred to by farmers' during the interviews, the various categories of health advisors included were determined as follows;

$\begin{array}{ll}\text { - } & \text { Veterinarian (Vet) } \\ \text { - } & \text { Technician (Tech) } \\ & \text { Sales representative/vendor from small natural product } \\ \text { - } & \text { Neighbour (Neigh) } \\ \text { - } & \text { Family member (Fam) }\end{array}$

\section{Statistical Analyses}

To detect the main correlations between variables, the Spearman rho was calculated for numerical data or the phicoefficient for qualitative data. Most variables were found to be inter-related and therefore analyses based on cluster analyses may be more appropriated since several variables are included in the construction of homogeneous clusters.We used Gower general similarity coefficient in cluster analyses (the only coefficient able to relate nominal and quantitative data ) available in Multivariate statistical package-MVSP 3.1, 2001. Gower coefficient ranges from 0 to 1 (maximum similarity). The results of the cluster analyses are presented in dendrograms constructed on unweighted centroid clustering. The unweighted clustering gives equal weight to each variable in each cluster. The centroid method is more appropriate when one is interested in chaining among clusters (a group of variables) rather than primary connections among individual variables [11]. Dendrograms are interpreted as follows: the cluster is validated when the Gower coefficient at the node is high. Due to the algorithm for regrouping variables or farms, the Gower coefficient could be negative on some instances. Factor analysis was used to relate the occurrences of health advisors in interviews and the veterinarian or Cam costs.

\section{RESULTS}

\section{Production and Global Health Indicators}

There was no difference in global health indicators between organic and conventional farms (Table 1) although there was a significant difference in their use of drugs. Organic farmers had lower veterinary costs and higher complementary feed and alternative medicine costs. They did not use hormones for reproduction (which are forbidden by organic regulations). They also used less feed concentrate per ewe.

The organic farms were regrouped together on the basis of these combined indicators (see Table 1); however the clusters were not fully satisfying (see negative or low positive values of Gower coefficient). Numerical productivity was associated with the level of concentrate food (Fig. 1). Mortality rates were associated with veterinary costs or complementary food and alternative medicine costs: the highest health costs corresponded to the lowest mortalities. The two significant (Spearman) correlations were: negative between CAM and ewes mortality and positive between CAM and numerical productivity.

\section{Health Advisors}

Veterinarians constituted $50 \%$ of the cited health advisors. Family and neighbours were mentioned in $21 \%$ and 
Table 1. Comparison of Characteristics Between Conventional and Organic Farms (Italicised Characteristic Indicate Significance at $\mathbf{p}<\mathbf{0 . 0 5}$ )

\begin{tabular}{|l|c|c|}
\hline \multicolumn{1}{|c|}{ Farm Characteristics } & Conventional (n=8) & Organic $(\mathbf{n}=7)$ \\
\hline \hline NUMPROD & $133^{*}(108-179)$ & $127(88-164)$ \\
\hline$(\%)$ MLAMB & $17(9-24)$ & $13(10-14)$ \\
\hline$(\%)$ MEWE & $7(4-11)$ & $6(5-6)$ \\
\hline$($ euro/ewe/year) VETCOST & $7.3(3.7-12.0)$ & $5.3(3.2-8.6)$ \\
\hline (euro/ewe/year) CAM & $3.0(0.8-6.0)$ & $6.6(1.5-19.3)$ \\
\hline (euro/ewe/year) HOR & $2.4(1.7-3.9)$ & 0.0 \\
\hline$(\%)$ FODAUT & $72(62-81)$ & $68(58-75)$ \\
\hline$($ kg/ewe/year) KGCONC & $157(989-232)$ & $114(78-144)$ \\
\hline
\end{tabular}

Mean (Minimum-Maximum) of each characteristics.

a

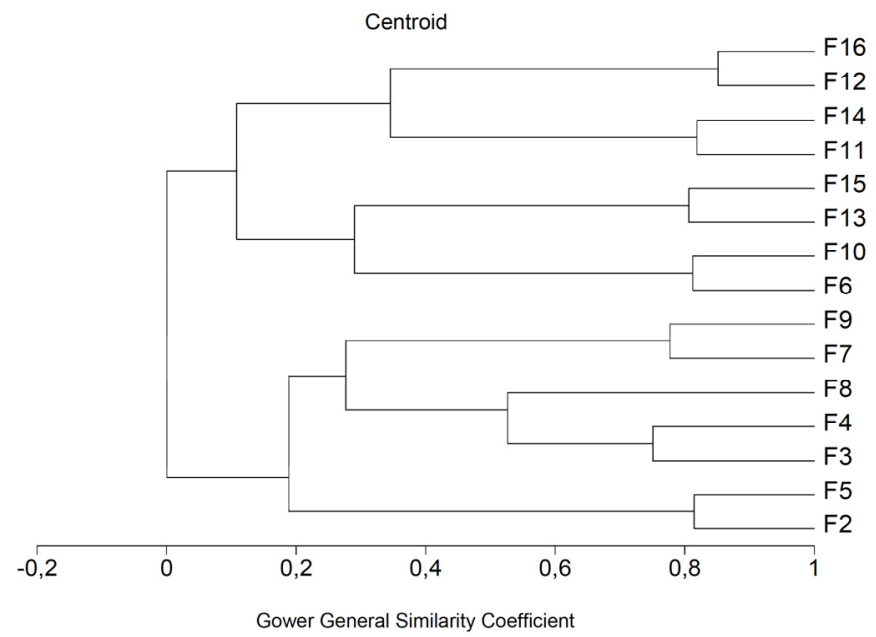

b

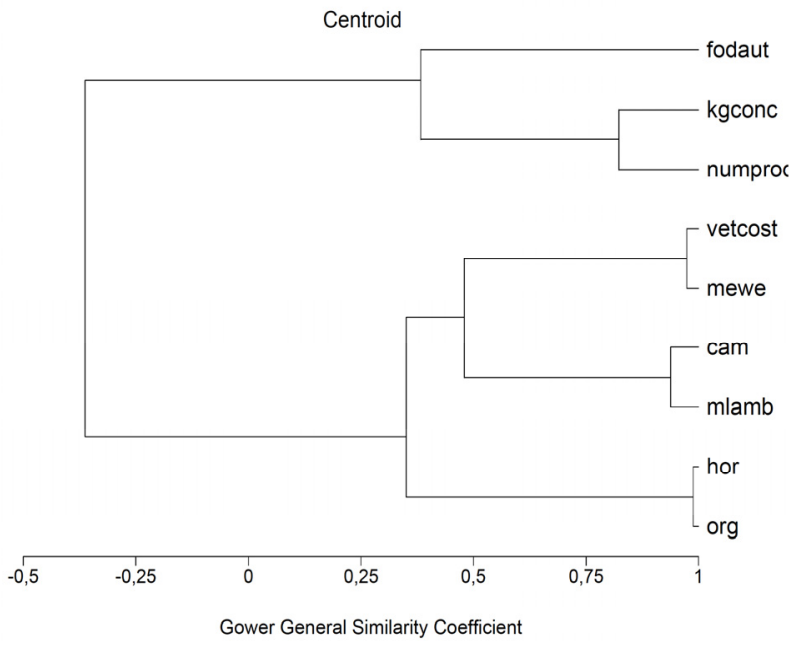

Fig. (1). Relationship between gross health indicators (Mlamb. Mewe. Numprod). Feed autonomy (Fodaut or Kgconc), expenses for animal health (Vetcost, Cam) or reproduction (Hor) in conventional and organic (F10-F16) meat sheep farms (a: farms; b: indicators).

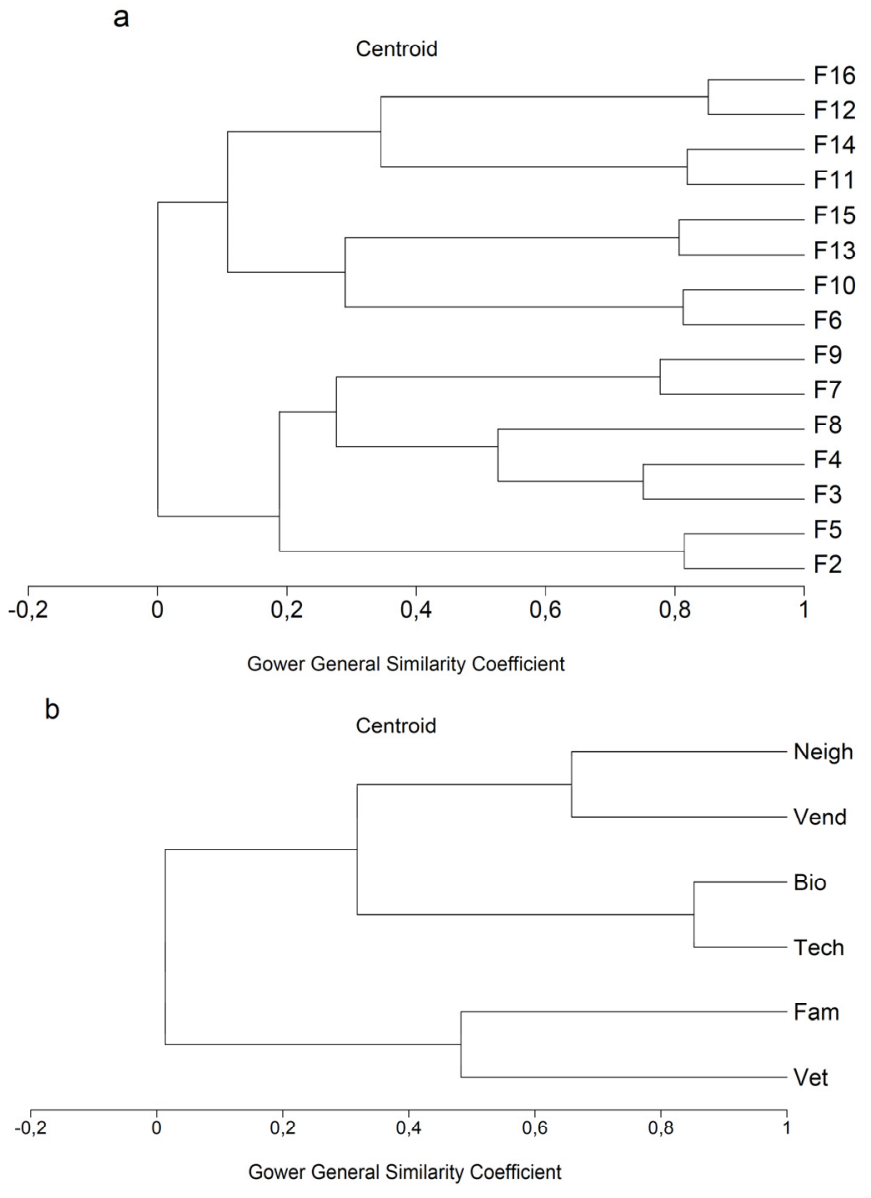

Fig. (2). Relationship between information/advisors in organic and conventional meat sheep farms as based on open interviews of farmers (occurrences of health advisor mentioned during interview) (a: farms and $\mathbf{b}$ : health advisors).

$17 \%$ of occurrences, respectively. The technicians and drug representatives had the lowest scores: $9 \%$ and $3 \%$ of occurrences respectively. The organic farms were regrouped together on the basis of the occurrences of the different health advisors with the exception of one organic farm, F10, which was included with the conventional ones based on his choice of advisor. The two clusters were not of high quality (see negative Gower values).

Veterinarians were considered by conventional farmers as a source for diagnostic opinion and for the provision of prescribed drug treatments. The F2 farm was actively participating in preliminary diagnostic assessments and requested the veterinarians to provide the relevant therapeutic responses. A similar attitude was recorded in the F6 farm. The F5 farm was reluctant to place complete trust in the veterinarians since the pharmaceutical companies providing the drugs were understood to be purely profit driven. All conventional farmers had a systematic plan for the date and drugs to be used for the treatments of gastro-intestinal helminths. The organic farmers however did not rely on a systematic plan and instead tended to adapt treatments according to the situation. Furthermore, organic farmers made attempts to find their own solutions to the health problems opposed to turning to veterinarians as a first response (F11, F12 and F16). One farm did not consider any advisor useful (F14) and resolved any problems independently. 
The real costs of treatments (VETCOST or CAM) were related to drug vendors (for CAM) or veterinarians or family advisors (for VETCOST), the VETCOST being high when CAM were low and vice versa (Fig. 3).

\section{Component Plot}

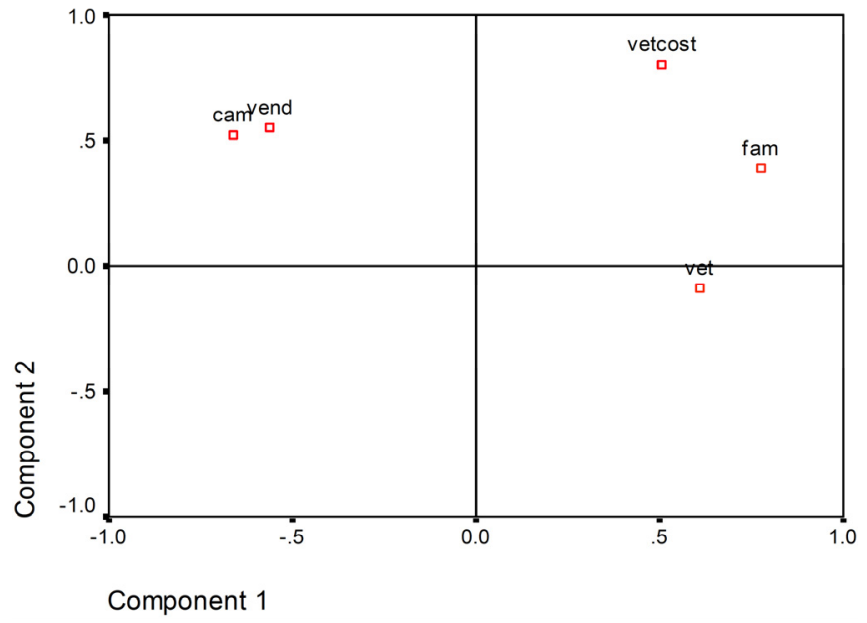

Fig. (3). Factor analysis of recorded costs in animal health and occurrences of the different health advisors (the two axes represent $67 \%$ of variance) (see Table 1 for codes).

\section{Farmers' Decision to Treat}

This was investigated only in relation to gastrointestinal nematode infections. The number of anthelmintic treatments in ewes was 4.06 (range: 2.5-5) and 1 (no variability), in conventional and organic farms respectively. The number of anthelmintic treatments in lambs was 7.4 (range 7-8) and 1.5 (12 ), in conventional and organic farms respectively. The number of anthelmintic treatments was substantially reduced in organic farms, and remained below the recommendations of organic regulations in the French or European context. The conventional farms followed the strategy of blanket treatment as proposed by veterinarians.

\section{DISCUSSION}

Prior to the comparison of sheep meat production between organic and conventional farms, the study recognized the influence that the organic regulations would have on the disease management decisions of farmers. What wasn't certain was what the consequent effect on production would be. In fact, a high similarity was observed in the production (numerical productivity) and gross pathological events (mortalities) among organic and conventional meat sheep farms. A similar finding was recorded in organic and conventional farmed dairy cows [12] in which milk cell counts and prevalence of clinical mastitis did not differ between farms even though the tools to detect clinical mastitis, the treatments of mastitis, the methods to dry off the cow and resulting production of milk per cow did differ. Maximum productivity is often perceived to be the major driving force behind a farmer's decisions, but the results of this study do not necessarily supportthis situation. High production is often achieved with high input in conventional farms by incorporating drugs and fertilizers on pastures while organic farmers promote "optimal" systems in which production and inputs may both be lower. Thus, analysis of numerical production in the study seems to be linked to costs of feed and food autonomy.
Then remains the key question in the study - how did the farmers achieve relatively similar results with so many different views (health advisors) and constraints (regulations) on their health management decisions? A possible hypothesis could include that the diseases were not negatively impacting production, therefore the health management strategy assumed was inconsequential. This however, is difficult to accept in view of gastrointestinal nematode infection in lambs [8] and clinical mastitis in cows [12]. An alternative hypothesis could be that CAM medicated animals are cured just as well as those treated with the usual allopathic synthetic drugs. As the CAMs are not yet validated by efficacy trials and many veterinarians will reject these drugs as useless until authorized [13], despite the fact a small number of veterinarians have endorsed their use [14], the question remains open [15]. The negative relationship between CAM and ewes mortality and positive relationship between CAM and numerical productivity would indicate a favourable influence (although possibly indirect) of the use of CAM. However, CAM trials on gastro-intestinal parasite infections in lambs, including efficacy, pathophysiological indicators and weight gains, did not show advantages of the homeopathic [16] or phytotherapy [17] treatments compared to the absence of treatment and we will not presently support this hypothesis. A final hypothesis is that diseases appear in a complex system; the farm and regulations between subsystems are subtle, and the same health result may occur from different cascades of interactions. There is some support for the last hypothesis [18]. The authors reported the economic benefits for dairy farmers participating in herd health and production management services by veterinarian programmes, but were not able to identify which components of the programme provided the economic benefits. The fact that meat sheep farm systems are complex has been investigated $[8,19]$ and is presented in Fig. (1b): the mortalities and numeric productivities were related to CAM, VETCOST, and KGCONC in a complex way. The influence of CAM on pathology indicators appeared to be more related to indirect system effect rather than on CAM efficacy per se.

The relationship between farmers and veterinarians can be organised: herd health and production management services by veterinarians have been introduced in many countries for conventional dairy cows and particularly in The Netherlands. The perceptions of both the farmers and the veterinarians are crucial if the relationship is to be satisfying and fulfil the objectives of improved health and economical benefits for both parties [20]. According to [21] "Respectful communication between the owner of the herd and other farmers as well as animal health and welfare professionals (veterinarians and advisors) is paramount." The perception of veterinarians by dairy cow farmers, even in conventional farms, falls within one of two groups: : one group sees the veterinarian as a repairman that identifies pathologies and cures them, and the other group demands technical advice for previously identified problems. Farmers who prefer the repairman approach identify problems they notice, and with the help of their veterinarians, clarify the underlying causes; the farmers have a limited and informal relationship with the veterinarians. Farmers preferring the veterinarian as a long term advisor already know the problem and require good technical advice on how to deal with the problem in the future, which means a formal contract between the farmer and the veterinarian [20]. The organic meat sheep farmers do not rely as frequently on their veterinarians (see 
VETCOST and CAM in Table 1) since they predominantly use $\mathrm{CAM}$ and deem their veterinarians not knowledgeable enough in alternative therapies to accept their guidance: they are considered as repairmen, mostly in acute diseases. The conventional meat sheep farmers have a mixed attitude: they want to obtain a pre-planned scheme for anthelmintic treatments, a vaccination programme (in which case using the long term advisor approach) but also use the veterinarians as repairmen in the case of acute and repeated diseases. They do not construct "animal health plans" [22] or "herd health and production management services" by veterinarians [20]. The limited engagement of both farmers' groups with vets on forward, farm-specific planning could be a serious impediment to such strategies.

Among the gross health indicators, mortalities were high in both conventional and organic farms (see Table 1). This is a widespread phenomenon observed in various species of animal production farms and in countries [23]. The meat sheep farmers did not comment on these high mortalities although they are costly and constitute an ethical issue. We could not decipher the origin in the lack of concern regarding lamb mortalities. It could be due to the idea that mortalities are but a part of the animal production industry and that no-cost effective solution is available. Or, that lamb mortality has ambiguous meanings although the death of a single lamb or twins may be considered as negative, the deaths among triple lambs may be easily accepted in view of their maintenance or potential drug costs. It is necessary to understand why such high mortalities are regarded as acceptable and the opinion of veterinarians or other advisors would be of interest to effectively manage mortality rates and reduce these high figures.

\section{ACKNOWLEDGEMENTS}

We are grateful to EU for funding Parasol Project and CIAB (Internal Committee for Organic Agriculture) from INRA for partial financing at the initiation of the project Kwakneonat. Discussions during the elaboration of the French sociological PAN ANR project on the motivations of farmers were fruitful. Comments on an earlier draft of the paper by Eric Morgan (Bristol University, UK) and Caroline Chylinski (INRA, Nouzilly, France) did improve the paper. The participation of interviewed farmers is greatly acknowledged.

\section{REFERENCES}

[1] Vaarst M, Roderick S, Lund V, et al. Organic principles and values: the framework of organic animal husbandry. p 1-10. In: Animal health and welfare in organic agriculture. Eds: Vaarst M, Roderick S, Lund V, et al. Lockeretz W. Wallingford, Oxon, UK: Cabi Publishing. CAB International 2004.

[2] IFOAM. International Federation of Organic Agriculture Movements. Principles of Organic Agriculture. http://www.ifoam.org/about_ifoam/ principles/index.html. Accessed on the 8th November 2010.

[3] Padel S, Röcklinsberg H, Schmid O. The implementation of organic principles and values in the European Regulation for organic food. Food Policy 2009; 24: 245-251.
[4] Thamsborg SM, Roderick S, Sundrum A. Animal health and diseases in organic farming: an overview. p 227-252. In: Animal health and welfare in organic agriculture. Eds: Vaarst M. Roderick S. Lund V. Lockeretz W. Wallingford, Oxon, UK: Cabi Publishing. CAB International 2004.

[5] Vaarst M, Martini A, Bennedsgaard TW, et al. Approaches to the treatment of diseased animals. $p$ 279-308. In: Animal health and welfare in organic agriculture. Eds: Vaarst M. Roderick S. Lund V. Lockeretz W. Wallingford, Oxon, UK: Cabi Publishing. CAB International 2004.

[6] Vaarst V, Padel S, Younie D, et al. Animal Health Challenges and Veterinary Aspects of Organic Livestock Farming Identified Through a 3 Year EU Network Project. Open Vet Sci J 2008; 2: 111-6.

[7] Huxley JN, Burke J, Roderick S, et al. Herd Health and Welfare Benchmarking on Organic Dairy Farms in South-West England. Cattle Practice 2003; 4: 331-3.

[7] Defra. 2004. Animal Health and Welfare Strategy for Great Britain. 43 p. http://ww2.defra.gov.uk/. Accessed on the $8^{\text {th }}$ November 2010 .

[8] Cabaret J, Benoit M, Laignel G, et al. Current management of farms and internal parasites by conventional and organic meat sheep French farmers and acceptance of targeted selective treatments. Vet Parasitol 2009; 164: 21-29.

[9] Cabaret J. Animal health problems in organic farming: subjective and objective assessments and farmers' actions. Livestock Prod Sci 2003; 80: 99-108

[10] Benoit M, Laignel G. Constraints under organic farming on French sheep meat productions: a legal and economic point of view with an emphasis on farming systems and veterinary aspects. Vet Res 2002; 33 : 613-624.

[11] Legendre P, Legendre L. Numerical ecology. Development in environmental modelling. Elsevier, Amsterdam 1998; p. 843.

[12] Ruegg P L. Management of mastitis on organic and conventional dairy farms. J Anim Sci 2009; 87:43-55.

[13] Overall K L, Dunham AE. Homeopathy and the curse of the scientific method. Vet J 2009; 180: 141-148.

[14] Roderick S, Ellis K. Organic Vet Home page. 2007. http://www.organic vet.co.uk/Default.htm. Accessed the $18^{\text {th }}$ of August 2009.

[15] Mathias E. Ethnoveterinary medicine in the era of evidence-based medicine: Mumbo-jumbo, or a valuable resource? Vet J 2007; 173 241-242.

[16] Tabel J, Sauvé C, Cortet J, et al. Fonder l'évaluation de la thérapeutique sur l'individu ou sur le groupe ? Un exemple : homéopathie et strongles digestifs des ovins. Innov Agro 2009; 4: 61-65

[17] Cabaret J, Gonnord V, Cortet J, et al. Moniezia chez l'agneau d'herbe : épidémiologie et tentative de contrôle par un traitement alternatif. Alter Agri 2005; 72: 4-7.

[18] Sol J, Renkema JA. A three-year herd health and management program on 30 Dutch dairy farms. 1. Objectives and main results. Vet Quart 1984; 6: 141-148.

[19] Berrag B, Ouzir M, Cabaret J. Meat sheep farm structure and the acceptability of targeted selective treatments for controlling digestivetract strongyles in Morocco. Vet Parasitol 2009; 164: 30-5.

[20] Lievaart JJ, Noordhuizen JPTM, Buckley D, et al. The marketing of herd health and production management services on Dutch dairy farms: Perceptions of dairy farmers and their veterinary surgeons. Irish Vet $\mathbf{J}$ 2008; 61: 668-676

[21] Vaarst M, Winckler C, Roderick S, et al. Animal health and welfare planning in organic dairy cattle farms. Open Vet Sci J 2011; (in press).

[22] Nicholas P, Jasinska A. 2008. Animal Health and Welfare Planning - A Review. Core organic, Aniplan. http://aniplan.coreportal.org3/? page_id=Accessed on 3d November 2010.

[23] Mellor DJ, Stafford KJ. Animal welfare implications of neonatal mortality and morbidity in farm animals. Vet J 2004; 168: 118-33. 